\title{
Decreased Baseline $\beta$-Lactamase Production and Inducibility associated with Increased Piperacillin Susceptibility of Pseudomonas cepacia Isolated from Children with Cystic Fibrosis ${ }^{1}$
}

\author{
CLAUDIO CHIESA, ${ }^{2}$ PAULINE H. LABROZZI, AND STEPHEN C. ARONOFF
}

Department of Pediatrics [C.C., P.H.L., S.C.A.], Case-Western Reserve University School of Medicine and the Division of Pediatric Infectious Diseases [S.C.A.], Rainbow Babies and Children's Hospital, Cleveland, Ohio

\begin{abstract}
The incidence of pulmonary infections in children with cystic fibrosis caused by Pseudomonas cepacia, an organism which may possess an inducible $\beta$ lactamase, has increased since 1978 . Seven of 13 sputum isolates of $P$. cepacia from children with cystic fibrosis were classified as inducible by quantitative enzyme production following preincubation with 100,200 , or $400 \mu \mathrm{g} / \mathrm{ml}$ of cefoxitin. The recovery of inducible strains tended to be associated with recent ceftazidime therapy. Susceptibility to aztreonam, ceftazidime, and piperacillin alone or combined with the $\beta$-lactamase inhibitors. YTR 830 or sulbactam, and isoelectric focusing for $\beta$-lactamase were performed. Inducible isolates produced significantly more $\beta$ lactamase than noninducible strains with or wihtout the addition of cefoxitin. Noninducible isolates were more susceptible than inducible isolates to $8 \mu \mathrm{g} / \mathrm{ml}$ of piperacillin, a difference that was eliminated with the addition of either $\beta$-lactamase inhibitor. Twelve of 13 strains produced a $\beta$ lactamase band in the $\mathrm{pH}$ range of 7.9-8.1; no differences in satellite patterns were noted between the two groups of organisms. Increased production of $\beta$-lactamase in the absence of an inducer may account for piperacillin resistance in $P$. cepacia in children with cystic fibrosis. (Pediatr Res 20: 1174-1177, 1986)
\end{abstract}

\section{Abbreviations}

MIC, minimum inhibitory concentrations pI, isoelectric point

Pulmonary infections caused by Pseudomonas cepacia in children with cystic fibrosis are frequently associated with progressive deterioration in pulmonary function (1). In one series of 38 children with $P$. cepacia isolated from their sputa, the fatality rate was $45 \%$ with approximately one-half of the deaths occuring within 3 months of colonization (2). The incidence of infection with this organism in the cystic population has gradually in-

Received March 3, 1986; accepted June 26, 1986.

Address correspondence to Stephen C. Aronoff, M.D., Division of Pediatric Infectious Diseases, Rainbow Babies and Children's Hospital, 2101 Adelbert Road, Cleveland, $\mathrm{OH} 44106$.

Supported by a grant from the Board of Trustees, Rainbow Babies and Children's Hospital.

${ }^{1}$ Presented in part at the 25th Interscience Conference on Antimicrobial Agents and Chemotherapy, Minneapolis, MN, October 1985.

${ }^{2}$ Current address IVth Department of Pediatrics, "La Sepienza" University of Rome, Institute of Experimental Medicine C.N.R., Viale R. Elena, 324, 00161, Rome, Italy. creased since 1978 and is now recovered from $20 \%$ of patients in some centers $(3,4)$.

Sputum isolates of $P$. cepacia from children with cystic fibrosis are resistant to most $\beta$-lactam agents in vitro. In an in vitro study comparing the susceptibilities of 62 consecutive sputum isolates, concentrations of $64 \mu \mathrm{g} / \mathrm{ml}$ of aztreonam and piperacillin were required to inhibit 79 and $87.1 \%$ of the bacterial population, respectively; $90 \%$ of the isolates were inhibited by $8 \mu \mathrm{g} / \mathrm{ml}$ of ceftazidime (5). In vitro, ceftazidime has proven more active against $P$. cepacia than piperacillin, aztreonam, HR-810, or BMY-28142 $(5,6)$.

Comparative clinical trials of ceftazidime and other drug regimens in the treatment of $P$. cepacia pulmonary infections in children with cystic fibrosis have not been performed. In a noncomparative study, 14 patients colonized with $P$. cepacia received ceftazidime; only six demonstrated clinical improvement (7). Ceftazidime treatment did not significantly reduce sputum concentrations of the organism. Kercsmar et al. (8) noted that six of six patients treated with ceftazidime improved. The effect of treatment on the sputum concentration of organisms was not reported in the latter study.

Although the mechanism(s) of resistance of $P$. cepacia to $\beta$ lactam agents is unclear, at least three, inducible, isoelectrically distinct $\beta$-lactamases have been identified (9-11). Hirai et al. (10) noted that the enzyme produced by Pseudomonas cepacia GN11164 hydrolyzed cefuroxime, cefotaxime, and cefamandole. The purpose of this study was to ascertain the role played by inducible enzyme production in resistance to piperacillin, aztreonam, and ceftazidime by sputum isolates of $P$. cepacia from patients with cystic fibrosis.

\section{MATERIALS AND METHODS}

Test strains. Thirteen isolates of $P$. cepacia recovered from the sputum of 12 children admitted to Rainbow Babies and Children's Hospital with pulmonary exacerbations of cystic fibrosis were studied. With one exception, all of the test strains were recovered between April and December 1984. Seven of the 13 test strains were recovered during or immediately after ceftazidime therapy; two isolates were recovered following ciprofloxacin therapy, one isolate after aztreonam therapy, and three isolates were obtained prior to parenteral antibiotic therapy. Pseudomonas aeruginosa ATCC 27853 was used to control the susceptibility and synergy experiments; Escherichia coli ATCC 35218 , which contains a TEM-1 (pI 5.4) and a chromosomal $\beta$-lactamase, was used as a marker for the isoelectric focusing experiments.

Cell-free enzyme preparations. The test strains were subcultured from frozen stock onto Mueller-Hinton agar, incubated 
overnight, and harvested into $10 \mathrm{ml}$ of Mueller-Hinton broth For the determination of $\beta$-lactamase inducibility, aliquots of the suspensions were diluted 10 -fold with fresh broth alone and in broth containing 100,200 , or $400 \mu \mathrm{g}$ of cefoxitin $/ \mathrm{ml}$ final solution. For isoelectric focusing, suspensions were diluted with fresh broth alone and in broth containing $200 \mu \mathrm{g}$ of cefoxitin $/ \mathrm{ml}$ of final solution. After a 2-h incubation in a shaking water bath at $35^{\circ} \mathrm{C}$, the organisms were harvested by centrifugation and washed twice with $0.05 \mathrm{M}$ phosphate buffer ( $\mathrm{pH} \mathrm{7.0)}$. The cell pellets were resuspended in $5 \mathrm{ml}$ of buffer, crushed in a French press at $6000-7000 \mathrm{psi}$, and centrifuged at $17,000 \times \mathrm{g}$ for $30 \mathrm{~min}$ at $4^{\circ} \mathrm{C}$. The supernatant was stored at $-20^{\circ} \mathrm{C}$.

Determination of enzyme inducibility. The $\beta$-lactamase activity of cell-free enzyme preparations preincubated in broth alone or 100,200 , or $400 \mu \mathrm{g}$ of cefoxitin/ $\mathrm{ml}$ of final solution was assayed by measuring the rate of nitrocephin hydrolysis at $482 \mathrm{~nm}$ over the first min $(12,13)$. The protein content of each sample was determined by the method of Bradford (14). Specific enzyme activity was expressed as $\mu \mathrm{mol}$ of product formed per min at $30^{\circ}$ $\mathrm{C} / \mathrm{mg}$ of protein (U/mg protein). Strains capable of increasing specific enzyme activity by $25 \%$ over baseline following preincubation with any concentration of cefoxitin were classified as inducible.

Sensitivity and synergy testing. The MIC of piperacillin (Lederle Laboratories, Wayne, NJ), aztreonam (E. R. Squibb and Sons, Princeton, NJ), and ceftazidime (Glaxo, Inc., Research Triangle, NC) against the 13 test organisms were determined by agar dilution (15). Inocula for susceptibility and synergy determination were prepared from overnight broth cultures diluted with fresh broth by nephelometry to yield a final inocula of $10^{5}$ $\mathrm{CFU} / \mathrm{ml}$. Resistance of the test organisms to the $\beta$-lactamase inhibitors sulbactam (Pfizer Central Research, Groton, CT) and YTR 830 (Taiho Pharmaceuticals, Ltd., Tokyo, Japan) was demonstrated by growth on Mueller-Hinton agar containing 32 $\mu \mathrm{g} / \mathrm{ml}$ of each compound. Two-fold serial dilutions of piperacillin, aztreonam, and ceftazidime were combined with $5 \mu \mathrm{g} / \mathrm{ml}$ of each of the $\beta$-lactamase inhibitors and incorporated into agar; a 4-fold increase or decrease in the MIC of the drug combination compared to the MIC of piperacillin, aztreonam, or ceftazidime alone were respectively defined as antagonism and synergism (16).

Isoelectric focusing of $\beta$-lactamase. Isoelectric focusing of the crude enzyme preparations was accomplished by the procedure described by Matthew et al. (17) using commercially prepared polyacrylamide gels ( $\mathrm{pH}$ range of 3.0 to 10.0 ) and a thermoelectrically cooled horizontal focusing apparatus. The $\beta$-lactamase bands were developed by overlaying the gel with filter paper soaked in $0.075 \%$ nitrocephin (BBL, Cockeysville, MD) and were recorded photographically on color slide film. The $\mathrm{pH}$ gradient for each gel was determined by the migration of known pI standard proteins (Isogel pI Markers, FMC Corporation, Rockland, ME) run in parallel on each gel and stained with Coomassie Blue.

Statistical analysis. The differences in antimicrobial therapy, susceptibility, and synergy were calculated by the Fisher exact test. Comparisons of mean specific enzyme activity between each group of organisms with and without cefoxitin preincubation was determined by the unpaired Student's $t$ test. Mean specific enzyme activities within each group of organisms following preincubation with $0,100,200$, or $400 \mu \mathrm{g}$ of cefoxitin $/ \mathrm{ml}$ of reaction mixture were compared using a one-way analysis of variance with repeated measures and Duncan's test (18).

\section{RESULTS}

$\beta$-Lactamase inducibility. Seven of the 13 test strains satisfied the criteria for inducibility; five of the inducible strains were recovered from patients receiving or recently treated with ceftazidime. The difference in isolation of inducible strains between ceftazidime recipients and nonrecipients approached but did not reach significance $(p=0.073)$. One inducible and one noninducible strain were isolated from the same patient.

The mean specific enzyme activities of the inducible and noninducible strains after preincubation with $0,100,200$, and $400 \mu \mathrm{g}$ of cefoxitin/ml of final reaction mixture are shown in Table 1 . The inducible isolates produced significantly more $\beta$ lactamase without cefoxitin induction than the noninducible isolates. Furthermore, induction with 100,200 , or $400 \mu \mathrm{g}$ of cefoxitin $/ \mathrm{ml}$ resulted in significantly higher specific $\beta$-lactamase activities for the inducible strains than the noninducible isolates. Following preincubation with any of the concentrations of cefoxitin tested, the noninducible strains did not significantly increase $\beta$-lactamase production compared to uninduced preparations as determined by analysis of variance ( $\mathrm{F}$ ratio $=2.07, p=\mathrm{NS}$ ). Conversely, a significant increase in enzyme activity following cefoxitin preincubation was observed for the inducible isolates (F ratio $=6.86, p<0.01$ ). By Duncan's test, preincubation with $200 \mu \mathrm{g}$ of cefoxitin/ml produced significantly higher specific enzyme activities than with broth alone $(p<0.01)$ or with 100 or $400 \mu \mathrm{g}$ of cefoxitin/ml $(p<0.05)$.

Quantitative $\beta$-lactamase production by the inducible strains following preincubation with broth alone or with broth containing 100,200 , or $400 \mu \mathrm{g}$ of cefoxitin/ml of final solution is shown in Table 2. Without induction, baseline enzyme concentrations ranged from 0.022 to $0.106 \mathrm{U} / \mathrm{mg}$ of protein. Preincubation with $200 \mu \mathrm{g} / \mathrm{ml}$ of cefoxitin produced specific enzyme activities which ranged from 0.049 to $0.314 \mathrm{U} / \mathrm{mg}$ of protein and induction indices which ranged from 1.25 to 3.82 .

Susceptibility and synergy. The effect of $\beta$-lactamase inducibility on the susceptibility of $P$. cepacia to piperacillin, aztreonam, and ceftazidime alone or combined with $5 \mu \mathrm{g} / \mathrm{ml}$ of either $\beta$-lactamase inhibitor is shown in Table 3 . All of the test strains were resistant to $32 \mu \mathrm{g} / \mathrm{ml}$ of sulbactam or YTR 830

Table 1. Quantitative $\beta$-lactamase production by inducible and noninducible isolates of $P$. cepacia

\begin{tabular}{ccccccc}
\hline & \multicolumn{3}{c}{ Specific enzyme activity* } & \\
\cline { 2 - 5 } $\begin{array}{c}\text { Cefoxitin } \\
\text { concentration } \\
(\mu \mathrm{g} / \mathrm{ml})\end{array}$ & $\begin{array}{c}\text { Inducible } \\
(n=7)\end{array}$ & & \multicolumn{2}{c}{$\begin{array}{c}\text { Noninducible } \\
(n=6)\end{array}$} & \\
\cline { 2 - 3 } & Mean & SD & & Mean & SD & $p$-value $\dagger$ \\
\hline 0 & 0.065 & 0.03 & 0.032 & 0.005 & $<0.025$ \\
100 & 0.098 & 0.08 & 0.024 & 0.007 & $<0.025$ \\
200 & 0.158 & 0.08 & 0.025 & 0.004 & $<0.005$ \\
400 & 0.086 & 0.07 & 0.030 & 0.03 & $<0.05$ \\
\hline
\end{tabular}

* Expressed as $\mu \mathrm{mol}$ of nitrocephin hydrolyzed per min per mgm of protein.

$\dagger$ Unpaired Student's $t$ test.

Table 2. Quantitative $\beta$-lactamase production in inducible strains of $P$. cepacia

\begin{tabular}{|c|c|c|c|c|c|c|c|c|}
\hline \multirow[b]{3}{*}{ Strain } & \multicolumn{8}{|c|}{ Concentration of cefoxitin $(\mu \mathrm{g} / \mathrm{ml})$} \\
\hline & \multicolumn{2}{|c|}{0} & \multicolumn{2}{|c|}{100} & \multicolumn{2}{|c|}{200} & \multicolumn{2}{|c|}{400} \\
\hline & SPE* & IInd $\dagger$ & SPE & IInd & SPE & IInd & SPE & IInd \\
\hline $72-70$ & 0.106 & & 0.254 & 2.41 & 0.314 & 2.97 & 0.260 & 2.46 \\
\hline $81-41$ & 0.048 & & 0.125 & 2.64 & 0.182 & 3.82 & 0.069 & 1.45 \\
\hline $73-40$ & 0.057 & & 0.045 & 0.79 & 0.188 & 3.29 & 0.043 & 0.75 \\
\hline $619 \mathrm{i}$ & 0.086 & & 0.021 & 0.24 & 0.136 & 1.58 & 0.048 & 0.56 \\
\hline $82-35$ & 0.022 & & 0.041 & 1.90 & 0.061 & 2.81 & 0.048 & 2.23 \\
\hline $82-14$ & 0.098 & & 0.167 & 1.71 & 0.178 & 1.82 & 0.11 & 1.11 \\
\hline $82-15$ & 0.039 & & 0.034 & 0.87 & 0.049 & 1.25 & 0.022 & 0.56 \\
\hline
\end{tabular}

${ }^{*}$ Expressed as $\mu \mathrm{mol}$ of nitrocephin hydrolyzed $/ \mathrm{min} / \mathrm{mg}$ protein at $30^{\circ}$ C.

$\uparrow$ Defined as SPE with inducer/SPE without inducer. 
Table 3. Inhibition of $\beta$-lactamase inducible and noninducible P. cepacia by piperacillin, aztreonam, and ceftazidime alone or combined with $5 \mu \mathrm{g} / \mathrm{ml}$ of $\beta$-lactamase inhibitors YTR 830 or sulbactam

\begin{tabular}{|c|c|c|c|c|c|c|c|c|c|c|c|}
\hline \multirow[b]{2}{*}{ Drug } & \multirow[b]{2}{*}{ Organisms } & \multirow{2}{*}{$\begin{array}{c}\text { Synergy } \\
\text { (no. of strains) }\end{array}$} & \multicolumn{9}{|c|}{ Cumulative MIC $^{*}$} \\
\hline & & & 1 & 2 & 4 & 8 & 16 & 32 & 64 & 128 & 256 \\
\hline \multirow[t]{2}{*}{ Piperacillin } & Inducible & & $0 / 7$ & $0 / 7$ & $1 / 7$ & $1 / 7$ & $4 / 7$ & $5 / 7$ & $7 / 7$ & & \\
\hline & Noninducible & & $0 / 6$ & $0 / 6$ & $2 / 6$ & $5 / 6$ & $5 / 6$ & $6 / 6$ & & & \\
\hline Piperacillin & Inducible & 4 & $2 / 7$ & $3 / 7$ & $3 / 7$ & $4 / 7$ & $5 / 7$ & $7 / 7$ & & & \\
\hline+ YTR 830 & Noninducible & 4 & $3 / 6$ & $4 / 6$ & $4 / 6$ & $4 / 6$ & $5 / 6$ & $6 / 6$ & & & \\
\hline Piperacillin & Inducible & 5 & $3 / 7$ & $4 / 7$ & $4 / 7$ & $5 / 7$ & $5 / 7$ & $5 / 7$ & $7 / 7$ & & \\
\hline + sulbactam & Noninducible & 4 & $2 / 6$ & $4 / 6$ & $5 / 6$ & $5 / 6$ & $5 / 6$ & $6 / 6$ & & & \\
\hline \multirow[t]{2}{*}{ Aztreonam } & Inducible & & $0 / 7$ & $0 / 7$ & $0 / 7$ & $0 / 7$ & $0 / 7$ & $1 / 7$ & $2 / 7$ & $3 / 7$ & $7 / 6$ \\
\hline & Noninducible & & $0 / 6$ & $0 / 6$ & $0 / 6$ & $0 / 6$ & $0 / 6$ & $0 / 6$ & $2 / 6$ & $2 / 6$ & $6 / 6$ \\
\hline Aztreonam & Inducible & 2 & $0 / 7$ & $0 / 7$ & $0 / 7$ & $0 / 7$ & $1 / 7$ & $2 / 7$ & $3 / 7$ & $3 / 7$ & $7 / 7$ \\
\hline+ YTR 830 & Noninducible & 1 & $0 / 6$ & $1 / 6$ & $1 / 6$ & $1 / 6$ & $1 / 6$ & $2 / 6$ & $3 / 6$ & $5 / 6$ & $6 / 6$ \\
\hline Aztreonam & Inducible & 1 & $0 / 7$ & $0 / 7$ & $0 / 7$ & $0 / 7$ & $0 / 7$ & $2 / 7$ & $3 / 7$ & $3 / 7$ & $7 / 7$ \\
\hline+ sulbactam & Noninducible & 2 & $0 / 6$ & $0 / 6$ & $0 / 6$ & $0 / 6$ & $1 / 6$ & $2 / 6$ & $4 / 6$ & $6 / 6$ & \\
\hline \multirow[t]{2}{*}{ Ceftazidime } & Inducible & & $0 / 7$ & $0 / 7$ & $0 / 7$ & $1 / 7$ & $1 / 7$ & $2 / 7$ & $4 / 7$ & $5 / 7$ & $7 / 7$ \\
\hline & Noninducible & & $0 / 6$ & $0 / 6$ & $0 / 6$ & $0 / 6$ & $0 / 6$ & $2 / 6$ & $5 / 6$ & $6 / 6$ & \\
\hline Ceftazidime & Inducible & 1 & $1 / 7$ & $1 / 7$ & $2 / 7$ & $2 / 7$ & $2 / 7$ & $2 / 7$ & $2 / 7$ & $4 / 7$ & $7 / 7$ \\
\hline + YTR 830 & Noninducible & 1 & $1 / 6$ & $1 / 6$ & $1 / 6$ & $1 / 6$ & $1 / 6$ & $1 / 6$ & $3 / 6$ & $5 / 6$ & $6 / 6$ \\
\hline Ceftazidime & Inducible & 1 & $0 / 7$ & $0 / 7$ & $1 / 7$ & $2 / 7$ & $2 / 7$ & $2 / 7$ & $3 / 7$ & $5 / 7$ & $7 / 7$ \\
\hline+ sulbactam & Noninducible & 3 & $0 / 6$ & $3 / 6$ & $3 / 6$ & $3 / 6$ & $3 / 6$ & $3 / 6$ & $5 / 6$ & $5 / 6$ & $6 / 6$ \\
\hline
\end{tabular}

* Expressed as number of strains inhibited and as $\mu \mathrm{g} / \mathrm{ml}$ of piperacillin, aztreonam, or ceftazidime.

alone. Significantly more noninducible strains were inhibited by $8 \mu \mathrm{g} / \mathrm{ml}$ of piperacillin than inducible strains $(p=0.048)$. No differences in susceptibility to ceftazidime or aztreonam alone were observed between the two groups of organisms.

Piperacillin- $\beta$-lactamase inhibitor combinations were effective equally against both the inducible and noninducible isolates. In particular, the difference in susceptibility between the two groups of organisms to piperacillin alone was eliminated in the presence of $\beta$-lactamase inhibitors. No differences in susceptibility to aztreonam or ceftazidime alone or combined with sulbactam or YTR 830 were observed. Compared to the inhibitory concentration of ceftazidime alone, the combination of ceftazidime-YTR 830 was antagonistic against two inducible and three noninducible isolates while ceftazidime-sulbactam was antagonistic against one noninducible strain.

Isoelectric focusing. Isoelectric focusing of uninduced and cefoxitin-induced cell free enzyme preparations of both groups of organisms were similar. All of the inducible strains produced at least one $\beta$-lactamase band which focused in the $\mathrm{pH}$ range of 7.9-8.1. Bands that focused in this range were noted in five of the six noninducible strains. There was no statistical difference in the number of satellite bands produced by either group of organisms with or without cefoxitin induction.

\section{DISCUSSION}

The production of inducible $\beta$-lactamases has been described for most enterobactericeae and pseudomonads $(11,17)$. Three enzymes from isolates of $P$. cepacia have been identified by isoelectric focusing. Matthew and Harris (11) identified an enzyme from $P$. cepacia $1599 \mathrm{E}$ with a pl of 8.0. Bidwell and Reeves (9) described an enzyme from strain $1872 \mathrm{E}$ with a pI of 8.5 . The $\beta$-lactamase partially purified from GN11164 had a pI of 9.0 (10). Of the 13 strains studied in this report, 12 produced bands which focused in the $\mathrm{pH}$ range of 7.8 to 8.1 . In a previous study, isoelectric focusing of $23 \mathrm{CF}$ isolates of $P$. cepacia from three centers in North America and 17 isolates from patients without cystic fibrosis and from the environment demonstrated $\beta$-lactamase bands in the 7.9 to $8.1 \mathrm{pH}$ range for most strains (19). The production of a $\beta$-lactamase band in this $\mathrm{pH}$ range appears to be common in $P$. cepacia isolated from all sources, including chil- dren with cystic fibrosis, and is independent of the inducibility of the organism.

Mutated strains of $P$. aeruginosa unable to produce significant amounts of chromosomally mediated $\beta$-lactamase are more susceptible to piperacillin and other $\beta$-lactamase-susceptible $\beta$-lactam agents than their respective parent strains with normal enzyme production $(20,21)$. Conversely, mutated strains of $P$. aeruginosa capable of increased $\beta$-lactamase production without induction (baseline concentrations) are more resistant to piperacillin than nonhyperproducing strains (22). Noninducible strains of $P$. cepacia have a diminished capacity to produce $\beta$ lactamase with or without induction compared to inducible strains. Not surprisingly, these noninducible isolates were more susceptible to piperacillin than the inducible strains, a difference that could be nullified with the addition of low concentrations of a $\beta$-lactamase inhibitor. Resistance of $P$. cepacia to aztreonam and ceftazidime was not associated with either $\beta$-lactamase inducibility or baseline $\beta$-lactamase activity as determined by this study. However, a mutated strain of $P$. cepacia which produces approximately 30 times as much $\beta$-lactamase as its inducible parent is significantly more resistant to ceftazidime and piperacillin than the parent strain (Aronoff S, unpublished observations). Resistance to piperacillin appears to require the baseline production of "moderate" concentrations of enzyme while resistance to ceftazidime requires even higher concentrations of $\beta$ lactamase. Changes in outer membrane permeability or in penicillin-binding proteins may also play a significant role in ceftazidime and aztreonam resistance. How all of these factors interact and contribute to $\beta$-lactamase resistance by $P$. cepacia is unknown.

Induction of chromosomal $\beta$-lactamase is a reversible phenomenon, with specific enzyme activities returning to baseline concentrations following withdrawal of the inducer (23). For $P$. cepacia, inducible strains are capable of significantly increasing $\beta$-lactamase production following preincubation with $200 \mu \mathrm{g} / \mathrm{ml}$ of cefoxitin and have increased baseline concentrations of enzyme compared to noninducible isolates. As a result, the ability of some strains of $P$. cepacia to produce increased amounts of $\beta$ lactamase following exposure to an inducer may be associated with increased baseline enzyme production which, in turn, leads to increased resistance to piperacillin. The frequency of recovery 
of inducible strains tends to occur more often in patients treated with ceftazidime and may account for the development of drug resistance during therapy.

\section{REFERENCES}

1. Isles A, Maclusky I, Corey M, Gold R, Prober C, Fleming P, Levison H 1984 Pseudomonas capacia infection in cystic fibrosis: an emerging problem. J Pediatr 104:206-2 10

2. Tablan OC, Chorba TL, Schidlow DV, White JW, Hardy KA, Gilligan PH, Morgan WM, Carson LA, Martone WJ, Jason JM, Jarvis WR 1985 Pseudomonas cepacia colonization in patients with cystic fibrosis: risk factors and clinical outcome. J Pediatr 107:382-387

3. Corey M, Allison L, Prober C, Levison H 1984 Sputum bacteriology in patients with cystic fibrosis. J Infect Dis 149:282

4. Thomassen MJ, Klinger JD, Badger ST, vanHeeckeran DW, Stern RC 1984 Cultures of thoracotomy specimens confirm usefulness of sputum cultures in cystic fibrosis. J Pediatr 104:352-356

5. Aronoff SC, Klinger JD 1985 Comparison of HR-810 and four antipseudomonal beta-lactam agents against Pseudomonas isolates from children with cystic fibrosis. J Antimicrob Chemother 15:545-549

6. Conrad DA, Scribner RK, Weber AH, Marks MI 1985 In vitro activity of BMY-28142 against pediatric pathogens including isolates from cystic fibrosis sputum. Antimicrob Agents Chemother 28:58-63

7. Gold R, Jin E, Levison H, Isles A, Fleming PC 1983 Ceftazidime alone and in combination in patients with cystic fibrosis: lack of efficacy in treatment of severe respiratory infections caused by Pseudomonas cepacia. J Antimicrob Chemother 12(suppl A):331-336

8. Kercsmar CM. Stern RC, Reed MD, Myers CM, Murdell D, Blumer JL 1983 Ceftazidime in cystic fibrosis: pharmacokinetics and therapeutic response. J Antimicrob Chemother 12(suppl A):289-295

9. Bidwell JL, Reeves DS 1981 Resistance of Pseudomonas species to beta-lactam antibiotics. Scand J Infect Dis 129(suppl):20-26

10. Hirai K, Inobe S, Inoue M, Mitsuhashi S 1980 Purification and properties of a new beta-lactamase from Pseudomonas cepacia. Antimicrob Agents Chemother 17:355-358

11. Matthew M, Harris AM 1976 Indentification of beta-lactamases by analytical isoelectric focusing: correlation with bacterial taxonomy. J Gen Microbiol
94:55-67

12. O'Callahan CH, Morris A, Kirby SM, Shingler AH 1972 Novel method for detection of beta-lactamases by using a chromogenic cepahalosporin substrate. Antimicrob Agents Chemother 1:283-288

13. Sykes RB, Matthew M 1979 Detection, assay, and immunology of betalactamase. In: Hamilton-Miller JMT, Smith JT (eds) Beta-Lactamases. Academic Press, Inc., London, pp 17-50

14. Bradford MM $1976 \mathrm{~A}$ rapid and sensitive method for the quantitation of microgram quantities of protein utilizing the principle of protein-dye binding. Anal Biochem 72:248-254

15. Washington JA, Sutter VA 1980 Dilution susceptibility test: agar and macrobroth procedures. In: Lennette EH, Balows A, Hausler JW, Truant JP (eds) Manual of Clinical Microbiology, 3rd ed. American Society for Microbiology, Washington, D.C., pp 453-458

16. Aronoff SC, Klinger JD 1984 In vitro activities of aztreonam, piperacillin, and ticarcillin combined with amikacin against amikacin-resistant $P$ seudomonas aeruginosa and $P$. cepacia isolates from children with cystic fibrosis. Antimicrob Agents Chemother 25:279-280

17. Matthew M, Harris AM, Marshall MJ, Ross GW 1975 The use of analytical isoelectric focusing for detection and identification of beta-lactamases. J Gen Microbiol 88:169-178

18. Godfrey K 1985 Comparing the means of several groups. N Engl J Med 313:1450-1456

19. Aronoff SC, Labrozzi PH. Differences in drug susceptibility between isolates of Pseudomonas cepacia recovered from patients with cystic fibrosis and other sources and its relationship to beta-lactamase focusing pattern. Pediatr Pulmonol (in press)

20. Bryan LE, Kwan S, Godfrey AJ 1984 Resistance of Pseudomonas aeruginosa mutants with altered control of chromosomal beta-lactamase to piperacillin, ceftazidime, and cefsulodin. Antimicrob Agents Chemother 25:382-384

21. Rosselet A, Zimmerman W 1973 Mutants of Pseudomonas aeruginosa with impaired beta-lactamase inducibility and increased sensitivity to beta-lactam antibiotics. J Gen Microbiol 76:455-457

22. Bell SM, Pham JN, Lanzarone JYM 1985 Mutation of Pseudomonas aeruginosa to piperacillin resistance mediated by beta-lactamase production. $\mathbf{J}$ Antimicrob Chemother 15:665-670

23. Okonogi K, Sugiura A, Kuno M, Higashide E, Kondo M, Imada A 1985 Effect of beta-lactamase induction on susceptibility to cephalosporins in Enterobacter cloacae and Serratia marcesans. J Antimicrob Chemother 16:31-42 